Academic Entrepreneurship for Medical and Health Scientists • Academic Entrepreneurship for Medical and Health Sciences

\title{
Nonprofit- and \\ Foundation-Sponsored \\ Research: Developing New \\ Models of Collaboration for \\ Research and Development
}

\section{Erin Esparza ${ }^{1}$}

${ }^{1}$ Perelman School of Medicine, University of Pennsylvania

Published on: Sep 27, 2019

DOI: 10.21428/b2e239dc.ecacdb9c

License: Creative Commons Attribution-NonCommercial-NoDerivatives 4.0 International License (CC-BY-NC-ND 4.0). 


\section{Topic Relevance by Timeline}

\section{Summary}

- In recent years there has been an increasing need for investigators to secure alternative sources of funding, and nonprofit organizations have become integral parts of the research and development process.

- Venture philanthropy is a relatively new concept of cooperation in which nonprofits not only fund research but also take a businesslike approach to product development, commercialization, and collaboration with industry partners.

- Potential opportunities that come with nonprofit funding can include better patient access, more early funding for research and development, and increased networking opportunities.

- Investigators must be prepared for potential pain points such as managing conflicts of interest, managing intellectual property, and ensuring prior art is accounted for during the application process.

- With proper management and transparency, involvement with a nonprofit foundation has the potential to be greatly beneficial to both the investigator and the foundation.

\section{Introduction}

Individual research centers and universities are often confronted with the predicament of providing enough funding to generate promising research and also creating an environment where a new therapy can be tested and potentially brought to market. The field of science, specifically medical research and therapy development, is notorious for a lack of integration and sharing of data/resources. This is a hindrance to the overall goal of developing therapies and technologies that can have an impact on human health because it creates an environment of isolation in research. Many researchers and their associated universities do not have the resources to develop and license new technology, as it is an expensive and potentially legally complicated 
endeavor. During times of decreasing government funding and tightened budgets, it becomes more important than ever to have additional sources of funding available. Nonprofit organizations and foundations have more recently stepped into the arena of research collaboration to function as the much-needed financial and organizational guide in the effort to get a therapy "from bench to bedside."

\section{Benefits and History of Research Funding}

Securing funding for research and development is not a new challenge to the scientific community. In pre-World War II United States, researchers commonly relied on contributions from universities and philanthropists, as money from the U.S. government was mostly directed toward agriculture and aeronautics (Jahnke). Prewar concerns in the 1940s caused the U.S. government to direct funding toward research and development in science, medicine, and technology. While the National Science Foundation (NSF) and the National Institutes of Health (NIH) are both government-run organizations that award grants for research and development, funding from those sources is highly competitive, and the amount of funds available depends on budget allocations from the government. Funding from nonprofits and foundations came from businessmen-turned-philanthropists such as Andrew Carnegie and John D. Rockefeller, Sr., via their own nonprofit organizations. Indeed, the Rockefeller Foundation made its first grant in 1913 to the American Red Cross, and this established a legacy of funding science and medical research that still continues today ("Our History=The Rockefeller Foundation"). Over time, more nonprofits and foundations were established in response to a specific problem that required attention, such as the Cystic Fibrosis (CF) Foundation, and these foundations, in turn, began seeing the necessity of providing funding to researchers who were working on the problems that the foundations wished to address. Perhaps the biggest hurdle that researchers have faced in the past is taking promising research from bench to bedside via funding for clinical trials, drug development, and guidance through the regulatory process. The importance of foundation involvement in funding research and development to this end cannot be overstated. According to the Cystic Fibrosis Foundation, the idea of "venture philanthropy" was started in 1998 by the CF Foundation to initiate the development of promising research with drug companies that had previously been reluctant to get involved in research when large profits were not guaranteed. This led to the creation of several drugs targeted toward CF and, most notably, in 2012 to a drug targeting the underlying cause of CF. This type of collaboration has become more commonplace, as 
organizations can not only guide promising research in the right direction, but they also stand to gain intellectual property (IP) ownership (see the chapter "Intellectual Property: Ownership and Protection in a University Setting"); this can result in more foundation funding for research on the back end if the foundation opts to sell its rights, as the CF Foundation did in 2014 ("Cystic Fibrosis Foundation").

In addition to nonprofits that fund disease-specific research, there are organizations, such as the Bill and Melinda Gates Foundation, that direct funding toward broader issues like access to healthcare and education in developing nations. Poverty-stricken areas require innovative solutions to a lack of basic needs such as clean water, sustainable farming practices, and disease eradication. Rather than implementing past approaches that had limited accountability and focus, the Gates Foundation aims to tackle problems with strategies specific to the problem at hand, and this also extends to their funding practices, which are considered by the Gates Foundation to be investments. A businesslike approach is also taken with grants, which are geared toward fiscal responsibility and productivity, and will most likely not be used to generate patents for profit. An example of this is a $\$ 1.3$ million grant awarded to the University of Wisconsin-Madison in 2008 that funded research into influenza pandemics. This research involved a collaboration with Lentigen Corp and it was agreed that any intellectual property generated during the study would be donated to the international research community ("WARF, UW-Madison Influenza Researcher, Lentigen Agree to Donate Technology"). According to the Gates Foundation, global access is a stipulation for any IP or product developments made with funding from the foundation; the new product or IP may be disseminated by a for-profit collaborator to the developed world but it must be made available globally "to the people that need them most”. (“Bill \& Melinda Gates Foundation").

An additional relevant example of nonprofit venture philanthropy is the Parker Institute, which was founded and funded by Napster founder Sean Parker. The goals of the Parker Institute are many and varied, but the overall mission is to speed the discovery of life-saving technologies. To do this, the institute partnered with several world-renowned research centers and the world's best researchers to provide not only financial support but also general management to streamline and guide crucial new research (McCullough). A key component of this large-scale collaboration is the sharing of data and ideas from labs that may formerly have had no connection. The Parker Institute is harnessing its considerable resources to put promising research in the best position to succeed by partnering with companies in the biotech and pharma industry, providing expertise on IP development and licensing, and managing clinical 
trials. The concept of such a collaborative environment with the availability of funds may prove to be revolutionary to the field of cancer research, and it could also change the way that new technologies are developed and licensed commercially. The Parker Institute saw the promise of a specific type of technology, cancer immunotherapy in this instance, and in the process of investing financially in this new technology they have also built a bridge between academia and industry at a time when industryfunded research in an academic setting is still in its infancy. The Novartis-Penn alliance is an example of a very recent collaboration between industry and academia that has been successful thus far, and the Parker Institute seeks to foster similar collaborations in the future. Alongside financial support, providing an environment in which similar collaborations may happen is perhaps one of the most important functions of nonprofit foundation involvement (Kannan). Of note is that the Parker Institute may request coownership of IP; this is discussed in more detail in later sections.

\section{Other Benefits of Joining a Nonprofit or Foundation}

There are many motivating factors in addition to funding that could encourage researchers to become involved with a nonprofit or foundation. Foundations and nonprofits are excellent sources of patient access, given that they most often have outreach to patients and their families, especially larger organizations such as the ALS Association. These large-scale nonprofits have vast resources and make community outreach and advocacy a priority in order to generate interest and funds. With a revenue of over $\$ 68$ million for FY2016, the ALS Association has the ability to fund promising research and connect families with potential therapies."'The ALS Association"). Even smaller nonprofits, such as the Emily Whitehead Foundation, have immense outreach abilities that can connect patients and their families with researchers in need of subjects for clinical studies. Not only is access to patients incredibly valuable, but researchers also benefit from the trust of the patients' families. Gaining trust from a parent to enroll their child on a clinical trial is easier when the parents have the comfort of knowing that a reputable foundation is endorsing the clinical trial and the associated researchers. Alex's Lemonade Stand Foundation (ALSF) is an example of improving outreach while also improving outcomes with focused research grants ("Alex's Lemonade Stand Foundation for Childhood Cancer"). According to the Michael J. Fox Foundation, 80\% of clinical trials finish late because of difficulty with research subject recruitment, and one-third will never even begin due to a lack of research subject recruitment "Clinical Trials 101: 
Understanding_Clinical Trials"). These statistics highlight the importance of patient access for product development. With a dedicated page for grants and a browsing tool for sponsored research on its website, the ALSF makes it clear that support for researchers is a number one priority, and this allows families to understand the research that is happening and the clinical trials that are available. While an organization such as ALSF may not be able to award grants large enough for a startup company to run on, early seed funding is crucial for getting started and for advancing research in an academic setting. Larger organizations such as the Juvenile Diabetes Research Foundation (JDRF) are able to make bigger moves financially and have made financial commitments to companies that are pursuing innovative solutions to health problems. For example, the JDRF has recently announced a \$42 million venture philanthropy fund geared toward "funding the best high-impact type-1 diabetes commercial opportunities" (Moses). The JDRF expands its reach even further by organizing symposium events and conferences for anyone involved in the field of diabetes research. Networking is a value added from foundations that cannot be overlooked, as it can provide access to new data and ideas as well as the opportunity for researchers to connect and share resources (“JDRF Grant Center”). Furthermore, a letter of support or demonstration of engagement with a patient-facing nonprofit/foundation may be viewed favorably by a federally sponsored scientific review group, such as an NIH study section, and thus be valuable for other grant applications submitted by an academic entrepreneur.

When engaging with a nonprofit, it is important to remember the responsibilities and expectations that can come along with funding. When seeking out a nonprofit with which to partner, it is important to ensure that there is an alignment of goals and that the nonprofit is seeking to contribute to research in a specific area. For example, the Juvenile Diabetes Research Center is an excellent resource for anyone with an interest in researching areas of metabolism, pancreatic function, or immunotherapy; however, it must be considered that funding is only provided for research that is targeted against type 1 diabetes (_JDRF-Type 1 Diabetes Research Funding_and Advocacy”).

There are many opportunities to make contacts and network with potential collaborators when searching for nonprofit partners (see the chapter "Formingand Maintaining_Meaningful Partnerships Between Academic Scientists and Corporations"). Depending on the area of research, these include numerous national and regional research symposiums as well as conferences, many of which are designed specifically for the purpose of networking. For example, the CF Foundation sponsors a North American CF Conference each year that brings together thousands of scientists 
and clinicians for the purpose of education and idea exchange (듷tic Fibrosis Foundation"). Upon securing a nonprofit organization with which to work, it is important to recognize that the nonprofit may be on a national or global scale, and this could require participation in specific events or campaigns. The foundation may require attendance or presentations at conferences or participation in publicity events and public outreach campaigns, in addition to other methods of oversight. As an example, Alex's Lemonade Stand Foundation states in their grants policy that a progress report must be submitted by the principal investigator each year, and this involves submitting details of budget expenditures as well as research progress, all of which is reviewed by the ALSF scientific advisory board (“Alex's Lemonade Stand Foundation for Childhood Cancer"). Additionally, a nonprofit will have policies on information and IP that must be adhered to; for example, the JDRF remains committed to disseminating scientific information to the public and requires that anyone using JDRF resources also agrees "to the publication and dissemination of all information and materials developed” (“JDRF Grant Center”). These are very important aspects to consider when deciding to partner with a nonprofit organization, and it is crucial for researchers to perform due diligence and fully understand the expectations when accepting foundation partnerships.

\section{Challenges When Collaborating with a Nonprofit or Foundation}

While the advantages of advancing research via collaboration with a nonprofit or foundation are obvious, there are also challenges that will go along with it. When advancing promising research and developing potential therapies or technology, there are always financial, regulatory, and legal issues at hand, and this fact is not negated due to the involvement of a foundation. Intellectual property is an important aspect of scientific entrepreneurship (covered in more detail in other chapters), and IP is a potential challenge when interacting with a nonprofit or foundation (see the chapters "Intellectual Property: Ownership and Protection in a University Setting" and "Intellectual Property: Commercializing in a University Setting"). In the more recently developed area of venture philanthropy, large foundations and nonprofits with significant financial contributions to research are seeking to benefit from commercially successful therapies paid for (at least in part) by the foundation itself. See Figure 1 for a comparison of traditional venture capital investing versus the venture philanthropy model that is being utilized by organizations such as the Cystic Fibrosis Foundation. 
Obviously, the topics of intellectual property and the associated royalties that are due to the investing partner (e.g., the Cystic Fibrosis Foundation) are critical issues for a researcher or startup company to consider. The foundation making the investment will inevitably want to also see profits from any commercially successful venture, and, according to Kristin Schneeman of the think tank FasterCures, nonprofits and foundations almost always opt to give royalty-bearing grants rather than making equity investments (Wolinsky). As noted in Nature Magazine, charities involved in venture philanthropy are providing crucial funding at a point when the risk is greatest, and they expect a return on their money (Ledford). 

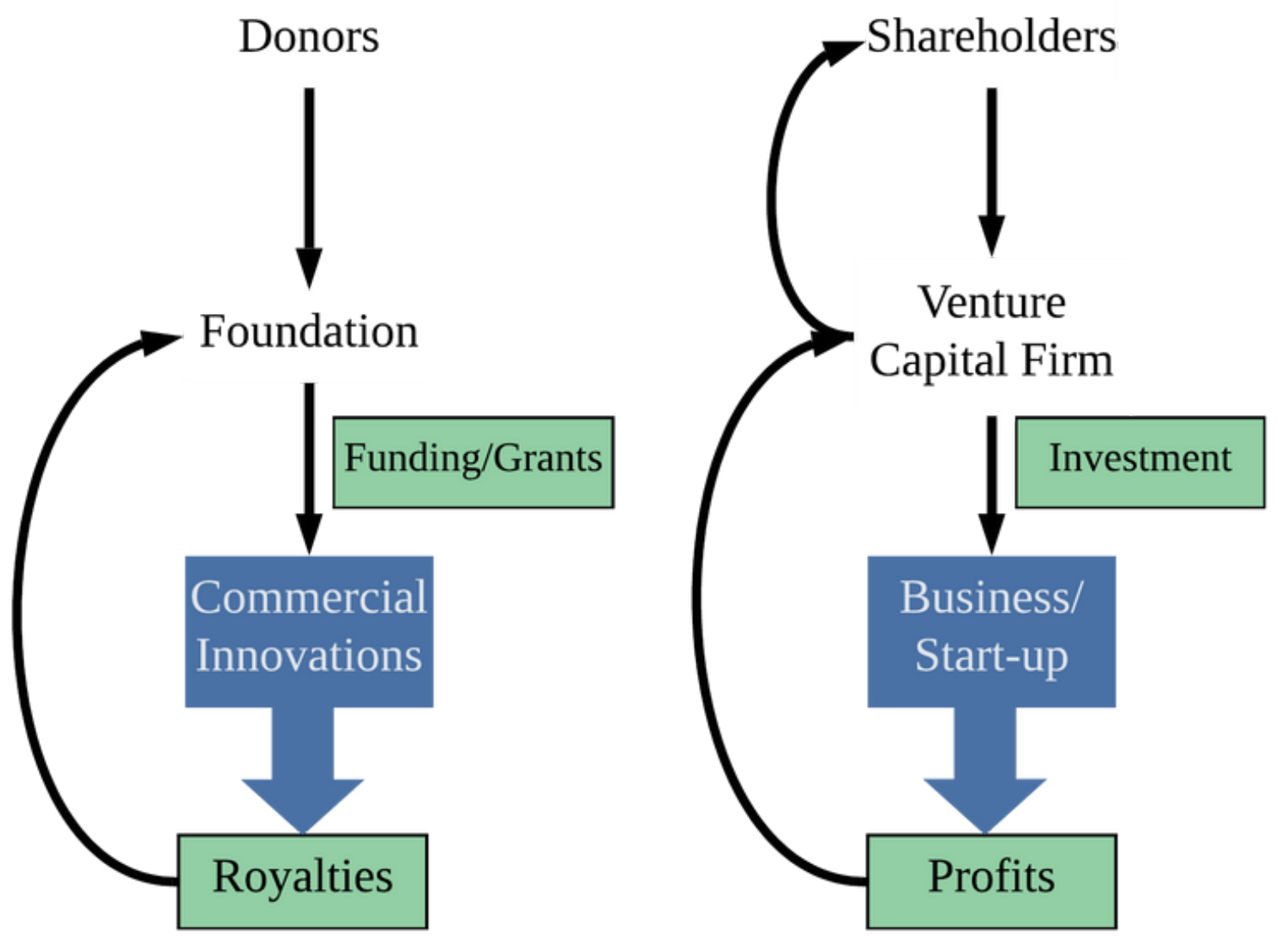

Figure 1

Revenue Flow to Funders in a Venture Philanthropy Model vs. Traditional Investment Model.

Legend: Items with no background are the source of funding. Green backgrounds are forms of funding. Blue backgrounds are the output of the source and form of funding. Profits/royalties are also returned to the academic entrepreneur and their institution, but the terms vary considerably depending upon the details of their contractual arrangements and are thus not shown here.

In addition, nonprofits and foundations that get financially involved in commercially directed ventures will often demand that an interruption license is signed in order to prevent IP from sitting unused by the startup; they also may resist getting financially involved in the various indirect costs associated with establishing IP and bringing it to market (Ledford). Another financial consideration is that some foundations do not allow researchers/research institutions to include overhead in their grants, or they place very low caps on the overhead. 
Conflict of interest is another challenge involved in nonprofit-sponsored research, for several reasons (see the chapter "Understanding_Conflict of Interest for Academic Entrepreneurs"). First, maintaining the trust of the patient/family base is of great importance to a charity and it is possible that becoming involved in venture philanthropy could jeopardize that trust. On the one hand, patients expect their respective foundations to use financial resources wisely and also to act as an advocate for the patients and their families. This includes fundraising and creating resources as well as utilizing those funds in a manner that will best help current and future patients. An example of how a conflict of interest can arise is the following scenario: A nonprofit makes financial contributions to the development of a drug with expectations of IP licensing revenue, but when the drug comes to market, the price is so high that the patients supporting the foundation experience financial hardships or have limited access (see Figure 2 below), while the foundation may have an incentive to encourage higher pricing since IP licensing revenue is usually tied to pricing. This is a hypothetical scenario; in general, one of the major advantages of working with philanthropic foundations is that their goals often prioritize the patients, and are better aligned with a hospital and health-related research than private sector investors and partners. Their desired outcomes often are to improve the lives of patients regardless of the financial return on investment (ROI). 


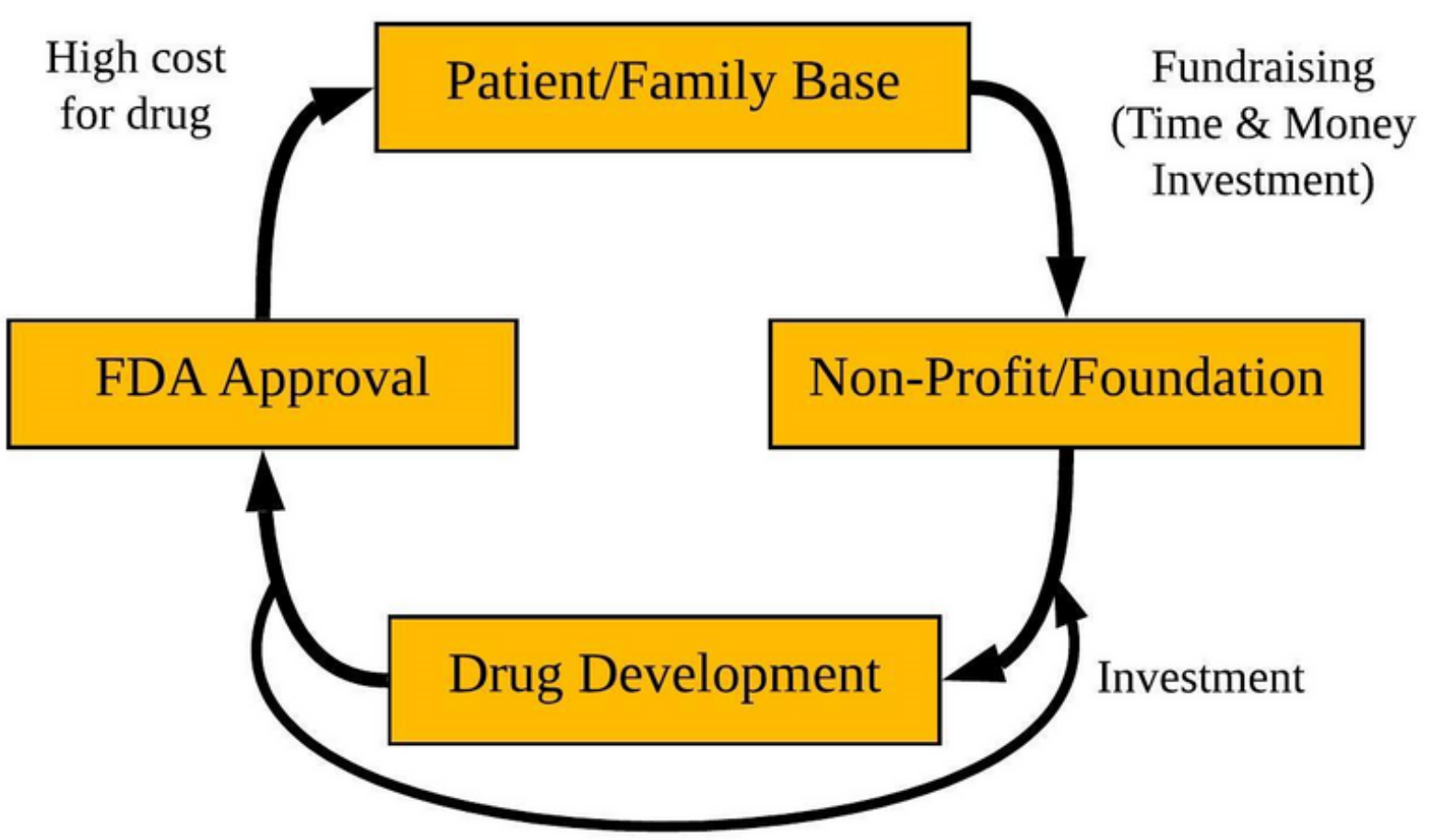

Royalties from IP go back to foundation

Figure 2

Potential Conflict of Interest Cycle for Charities.

To attempt to avoid the scrutiny that goes along with intellectual property benefits, nonprofits must certainly have a clear conflict of interest policy in place, as well as transparency with financial documents. In this instance, if a nonprofit wishes to invest and see returns as a normal for-profit business, then it is necessary for it to function as such, which requires a clear leadership hierarchy and honesty with the patients and families who provide grassroots financial support. An additional subject for consideration by all parties is the disclosure and the management of IP, as well as potential prior art issues. As stated by the Oklahoma State University Technology Development Center, grant applications can be recognized legally as prior art, and this is crucial to any investigator and/or nonprofit with an interest in patent filing and IP development ("Grant Applications as Prior Art”). It is extremely important for all parties involved in funding to understand the ramifications of filing grant applications as well as the practices of seeking patents and developing technology; for example, if a nonprofit or foundation posts grant applications on their website, this may represent prior art and compromise future IP (see the chapter "Does My Invention Already_Exist? 
Conducting_a Patent / Prior Art Search"). The applicant should read all disclosure information provided by the foundation prior to submitting any information; while most large grant-awarding foundations will provide disclosure and confidentiality policies on their website, applicants should always work with the appropriate foundation contact to clarify any questions. This subject is another matter that requires some forethought and research on the part of the applicant prior to becoming legally and financially involved with a nonprofit.

\section{Conclusion}

In an environment of ever-changing financial states and changes to organizational structures and regulations, it is important for researchers to explore all avenues for funding opportunities. Nonprofit foundations can be an excellent resource for investigators seeking funding for research and development. As with most funding sources, there are legal and financial points to consider prior to getting involved with a foundation or nonprofit; however, most potential pain points can be dealt with or avoided as long as there is transparency from all parties throughout the process. Gaining support from a foundation can have many positive impacts on research beyond simply providing funding. A well-regarded and well-funded foundation may have resources that can provide investigators with more networking opportunities, increased interaction with partner labs and organizations, increased access to patients, guidance through the regulatory process, and industry connections. These numerous benefits could be the difference between simply having a concept and being able to conduct the necessary research to fully develop that concept into a marketable drug or device that can impact human health. Gaining support from a nonprofit could be a mutually beneficial relationship for the investigator and the foundation that could provide long-term returns both developmentally and financially.

\section{Resources}

\section{Oppen Education Database}

- A website providing information and links to potential funding sources.

\section{$\underline{\text { United States Patent and Trademark Office website }}$}

- Information on patents, intellectual property, and additional resources for inventors. 
Science Philanthropy_Alliance

- A community of philanthropists committed to funding science.

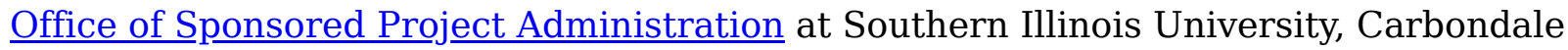

- A university website containing a list of foundations and nonprofit funding agencies.

\section{GuideStar, Directory of Charities and Nonprofit Organizations}

- An extensive list of charitable foundations.

Venture Philanthropy_Strategies to Support Translational Research: Workshop_ Summary.

- Institute of Medicine Forum on Neuroscience and Nervous System Disorders. "Introduction." Venture Philanthropy Strategies to Support Translational Research: Workshop Summary. National Academies Press, 2009.

\section{Strategies for Navigating Intellectual Property.}

- Breakthrough Business Models: Drug Development for Rare and Neglected Diseases and Individualized Therapies: Workshop Summary

- Institute of Medicine Forum on Drug Discovery, Development, and Translation. Breakthrough Business Models: Drug Development for Rare and Neglected Diseases and Individualized Therapies: Workshop Summary. National Academies Press, 2009.

The contents of this chapter represent the opinions of the chapter authors and editors. The contents should not be construed as legal advice. The contents do not necessarily represent the official views of any affiliated organizations, partner organizations, or sponsors. For programs or organizations mentioned in this chapter, the authors encourage the reader to directly contact the relevant organization for additional information. 


\section{Citations}

1. Jahnke, Art. "The History and Future of Funding for Scientific Research." Boston University, 6 Apr. 2015, http://www.bu.edu/articles/2015/funding-for-scientificresearch. $\doteq$

2. "Our History-The Rockefeller Foundation." The Rockefeller Foundation, https://www.rockefellerfoundation.org/about-us/our-history/. Accessed 24 Aug. 2019. $\Xi$

3. "Cystic Fibrosis Foundation." Cystic Fibrosis Foundation, https://www.cff.org/. Accessed 15 Aug. 2019.

4. “WARF, UW-Madison Influenza Researcher, Lentigen Agree to Donate Technology.” University of Wisconsin-Madison, 25 Mar. 2008, https://news.wisc.edu/warf-uw-madison-influenza-researcher-lentigen-agree-todonate-technology $/ . \subseteq$

5. “Bill \& Melinda Gates Foundation.” Bill \& Melinda Gates Foundation, https://www.gatesfoundation.orgL. Accessed 15 Aug. 2019. 6. McCullough, Marie. “Tech Giant Sean Parker Launches Penn’s Cancer Immunotherapy Center." The Philadelphia Inquirer, 26 Oct. 2016, https://www.inquirer.com/philly/health/cancer/Tech-giant-Sean-Parker-launchesPenns-cancer-immunotherapy-center.html. $\bullet$

7. Kannan, Vibha. 'A 'Historic' Cancer Treatment Designed by Penn Researchers Just Got Approved by the FDA." The Daily Pennsylvania, 31 Aug. 2017, https://www.thedp.com/article/2017/08/a-historic-cancer-treatment-designed-by-pennresearchers-just-got-approved-by-the-fda.

8. "The ALS Association." The ALS Association, http://www.alsa.orgL. Accessed 15 Aug. 2019. $\subseteq$

9. "Alex's Lemonade Stand Foundation for Childhood Cancer." Alex's Lemonade Stand Foundation for Childhood Cancer, https://www.alexslemonade.org/. Accessed 15 Aug. 2019.

10. “Clinical Trials 101: Understanding Clinical Trials.” Fox Trial Foundation, https://foxtrialfinder.michaeljfox.org/understanding-clinical-trials/clinical-trials-101/. Accessed 24 Aug. 2019. $\_$ 
11. Moses, Sue-Lynn. "A Diabetes Foundation Jumps into Venture Philanthropy in a Big Way." Inside Philanthropy, 12 Feb. 2017, https://www.insidephilanthropy.com/home/2017/2/12/juvenile-diabetes-researchfoundation. $\doteq$

12. “JDRF Grant Center.” Juvenile Diabetes Research Foundation (JDRF), http://grantcenter.jdrf.org/? ga=2.79197842.76963957.15667003071466655577.1566700307. Accessed 24 Aug. 2019.

13. “JDRF-Type 1 Diabetes Research Funding and Advocacy." The Juvenile Diabetes Research Foundation, https://www.judrf.orgL. Accessed 15 Aug. 2019.

14. Wolinsky, Howard. "Venture Philanthropy Straddles Two Worlds." Managed Care Magazine, 12 June 2017, https://www.managedcaremag.com/archives/2017/6/venture-philanthropy-straddlestwo-worlds..

15. Ledford, Heidi. “Charities Seek Cut of Drug Royalties.” Nature, vol. 475, no. 7356, July 2011, pp. 275-76, https://doi.org/10.1038/475275a.

16. “Grant Applications as Prior Art." Technology Development Center, https://tdc.okstate.edu/grant-applications-prior-art. Accessed 20 Aug. 2019. 